\title{
Effect of Substrate Temperature on Electrical and Optical Properties of Al Doped ZnO Thin Films by Continuous Composition Spread
}

\author{
Keun Jung ${ }^{1}$, Jin-Ju Lee1, Won-Kook Choi², Seok-Jin Yoon¹, and Ji-Won Choi 1,+
}

\begin{abstract}
$\mathrm{Al}$ doped $\mathrm{ZnO}(\mathrm{AZO})$ thin films were deposited at different substrate temperatures by a continuous composition spread(CCS) method. Various compositions of $\mathrm{Al}$ doped $\mathrm{ZnO}$ thin films deposited at substrate temperatures between 0 and $250{ }^{\circ} \mathrm{C}$ were explored to find excellent electrical and optical properties. The AZO thin film deposited at $100{ }^{\circ} \mathrm{C}$ had the lowest resistivity, $9 \times 10^{-4} \Omega \cdot \mathrm{cm}$ and its average transmittance at the 400 to $700 \mathrm{~nm}$ wavelength region was $92 \%$. Optimized composition of the AZO thin film which had the lowest resistivity and high transmittance was $3.13 \mathrm{wt} \% \mathrm{Al}$ doped $\mathrm{ZnO}$.
\end{abstract}

Keywords : Continuous Composition Spread, Transparent Conducting Oxides, Al Doped ZnO

\section{INTRODUCTION}

Transparent conducting oxide(TCO) films are materials, which are electrically conductive and highly transparent to visible light. TCOs have been extensively investigated because of their important technological applications in regards to many fields such as organic light emitting diodes(OLEDs), flat panel displays(FPDs), surface acoustic waves(SAW) and solar cells[1-4]. Zinc oxide $(\mathrm{ZnO})$ thin films have been considered as transparent conducting films because they are more stable against hydrogen plasma, more abundant, and less expensive than indium tin oxide(ITO) which has superior electrical and optical properties in this field.

$\mathrm{ZnO}$ has intrinsic defects, such as $\mathrm{Zn}$ interstitials $\left(\mathrm{Zn}_{\mathrm{i}}\right)$ and $\mathrm{O}$ vacancies $\left(\mathrm{V}_{\mathrm{o}}\right)$. They allow non-stoichiometric $\mathrm{ZnO}$ to have intrinsic n-type conductivity with high electron densities. However, electrical properties of $\mathrm{ZnO}$ films are not good in comparison with ITO when native point defects don't affect to $\mathrm{ZnO}$ as donors efficiently. So, many researchers have been focused on the intentional doping in $\mathrm{ZnO}$, such as $\mathrm{Al}$ doped $\mathrm{ZnO}(\mathrm{AZO})$ and $\mathrm{Ga}$ doped $\mathrm{ZnO}$ (GZO). Especially, Al doped $\mathrm{ZnO}$ films have some advantages such as high temperature stability and higher transmittance even at near infrared wavelengths compared

${ }^{1}$ Electronic Materials Research Center, Korea Institute of Science and Technology

${ }^{2}$ Interface Control Research Center, Korea Institute of Science and Technology

${ }^{+}$Corresponding author: jwchoi@kist.re.kr

(Received : Jun. 12, 2012, Revised : Jul. 9, 2012, Accepted : Jul. 10, 2012) to ITO[5]. Many researchers have reported about AZO thin films according to the different doping content of Al[6-8]. However, there is a still controversy concerning the optimized $\mathrm{Al}$ doping concentration in $\mathrm{ZnO}$. In this study, a full range of AZO compositions and various growth temperatures of AZO thin films were investigated by continuous composition spread(CCS). CCS is a thin film growth method for various compositions on a substrate with a binary or ternary composition spread [9-13]. Full compositions of $\mathrm{Al}_{\mathrm{x}} \mathrm{Zn}_{1-\mathrm{x}} \mathrm{O}$ are deposited on a glass substrate at different temperature by CCS. Especially, we focused on the effect of various substrate temperatures on the physical properties of varying $\mathrm{Al}$ doped $\mathrm{ZnO}$ films by continuous composition spread. Also, their properties such as structural, electrical and optical properties were examined.

\section{DESIGN}

$\mathrm{Al}$ doped $\mathrm{ZnO}$ thin films were deposited on a square sample $(15 \mathrm{~cm} \times 2 \mathrm{~cm})$ (eagle 2000 , corning) at various substrate temperatures by off-axis sputter-CCS shown as Fig. 1. The off-axis sputter CCS has three independent radio frequency $(\mathrm{RF})$ magnetron sputtering guns, which are located at $90^{\circ}$ to the substrate. A zinc oxide(purity 99.99 $\%$, CERAC) and $\mathrm{Al}_{2} \mathrm{O}_{3}$ (purity $99.99 \%$, CERAC) targets were used to explore the superior electrical and optical properties of AZO. The sputtering chamber was pumped down to $2.66 \times 10^{-4}$ Pa by a rotary pump and turbo 
molecular pump. The sputtering was performed at a pressure of $2.66 \mathrm{~Pa}$ in a pure argon atmosphere. The $\mathrm{Al}_{2} \mathrm{O}_{3}$ and $\mathrm{ZnO}$ targets were powered by independent $\mathrm{RF}$ supplies $\left(\mathrm{Al}_{2} \mathrm{O}_{3}: 300 \mathrm{~W}, \mathrm{ZnO}: 150 \mathrm{~W}\right)$ to achieve the desired composition range on a substrate. In order to investigate the substrate temperature dependence of the electrical and optical properties of the AZO-CCS films, AZO-CCS thin films were deposited at substrate temperatures between 0 and $250{ }^{\circ} \mathrm{C}$. The thickness of the thin films was examined through cross section observation by FE-SEM(XL-30, FEG). The crystal structure of AZO thin films was investigated by X-ray diffraction(D/MAX2500, RIGAKU). Electrical properties of AZO thin films were measured using the four-point probe method(MCPT600, Mitsubishi chemical) using the automatic probe station(19S, TEL) and the Hall Effect measurement system(HMS-3000, Ecopia). Optical transmittance was measured in the range of $200-900 \mathrm{~nm}$ by UV/VIS spectrometer(Lambda 18, Perkin Elmer) and using Eagle 2000 glass as the reference. The thickness of the thin films was examined through cross section observation by FESEM(XL-30 FEG field emission scanning electron microscope). The optimized composition and thickness of thin films were characterized by Rutherford backscattering spectroscopy(RBS)(6SDH2, NEC).

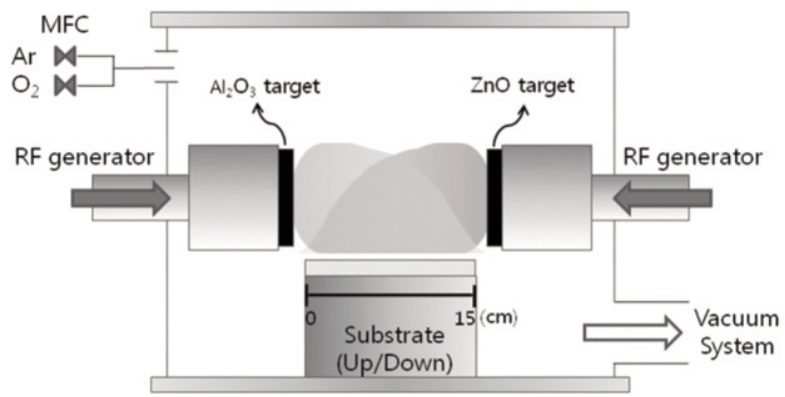

Fig. 1. Schematic diagram of the continuous composition spread (CCS) system.

\section{RESULTS AND DISCUSSIONS}

Fig. 2 shows the thickness profiles of single $\mathrm{Al}_{2} \mathrm{O}_{3}$, and single $\mathrm{ZnO}, \mathrm{Al}_{2} \mathrm{O}_{3}-\mathrm{ZnO}$ thin films deposited at an $\mathrm{RF}$ power of 300 and $150 \mathrm{~W}$ for $\mathrm{Al}_{2} \mathrm{O}_{3}$ and $\mathrm{ZnO}$ targets, respectively. The thickness profiles for each single $\mathrm{Al}_{2} \mathrm{O}_{3}$ and $\mathrm{ZnO}$ are directly related to the composition of binary $\mathrm{Al}_{2} \mathrm{O}_{3}-\mathrm{ZnO}$ films as a function of position. The deposition rates and thickness of single $\mathrm{Al}_{2} \mathrm{O}_{3}$ and $\mathrm{ZnO}$ thin films were measured by cross-sectional SEM analysis. In the offaxis sputter-CCS system, the deposition rates and thickness of thin films relate to the distances from the target. When the distances from the target were increased, the deposition rates and thickness were decreased as shown in Fig. 2. The thickness profile of $\mathrm{Al}_{2} \mathrm{O}_{3}-\mathrm{ZnO}$ binary CCS film measured by SEM had a similar tendency with the sum of single $\mathrm{Al}_{2} \mathrm{O}_{3}$ and single $\mathrm{ZnO}$ thickness profiles, which were measured by SEM. The difference between the thickness of $\mathrm{Al}_{2} \mathrm{O}_{3}-\mathrm{ZnO}$ binary CCS and the summation of $\mathrm{Al}_{2} \mathrm{O}_{3}$ and $\mathrm{ZnO}$ single CCS is due to the ballistically and diffusively deposited particles of $\mathrm{Al}_{2} \mathrm{O}_{3}$ and $\mathrm{ZnO}[14]$.

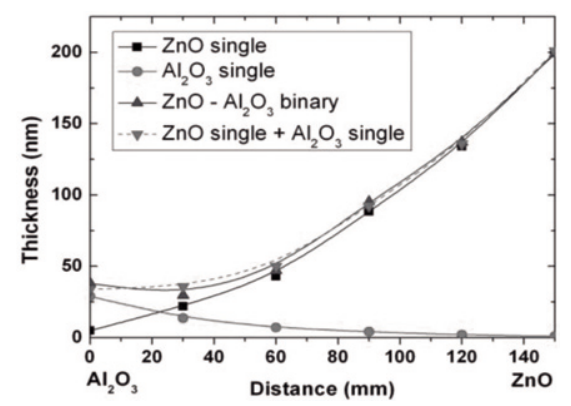

Fig. 2. Thickness profile of $\mathrm{ZnO}-\mathrm{Al}_{2} \mathrm{O}_{3}$ thin films on a glass substrate by off-axis sputter-CCS.

Fig. 3(A) shows sheet resistance maps of AZO-CCS thin films deposited at various substrate temperatures between 0 and $250^{\circ} \mathrm{C}$. Each position of the sheet resistance map had a different value horizontally because of their different $\mathrm{Al}$ doped $\mathrm{ZnO}$ compositions. Especially, the resistivity of the areas from 0 to $9 \mathrm{~cm}$ for all thin films were higher than 1.0 $\times 10^{-2} \Omega \cdot \mathrm{cm}$ or overloaded because of the $\mathrm{Al}_{2} \mathrm{O}_{3}$ thickness which has insulating properties $\left(\mathrm{Al}_{2} \mathrm{O}_{3}\right.$ rich region). However, the resistivity of areas from 9 to $15 \mathrm{~cm}$ of all thin films except those deposited at 200 and $250{ }^{\circ} \mathrm{C}$ were lower than $1.0 \times 10^{-2} \Omega \cdot \mathrm{cm}$ ( $\mathrm{ZnO}$ rich region doped with $\mathrm{Al}_{2} \mathrm{O}_{3}$ appropriately). We focused on areas of $\mathrm{AZO}$ thin films deposited near the $\mathrm{ZnO}$ target because the purpose of this study is to find excellent electrical properties by continuous composition spread. We indicated a red circle(position of $10 \mathrm{~cm}$ ) on sheet resistance maps of AZO-CCS thin films because they had the lowest sheet resistance in Fig. 3(A). Fig. 3(B) shows the resistivity(position of $10 \mathrm{~cm}$ for each AZO-CCS thin film) of AZO thin films prepared at substrate temperatures between 0 and $250{ }^{\circ} \mathrm{C}$. It was found that the resistivity decreased as the substrate temperature increased to $100^{\circ} \mathrm{C}$. At this temperature, the lowest values for the resistivity $(9$ 
(A)

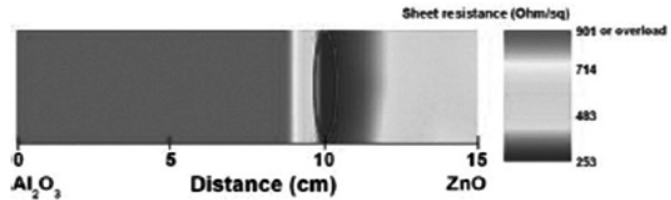

(a)

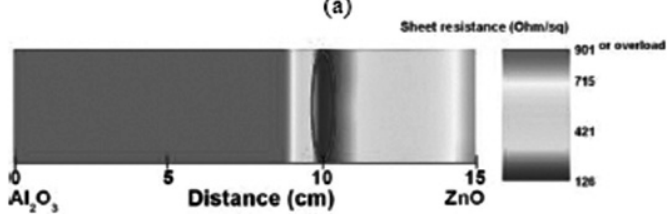

(b)

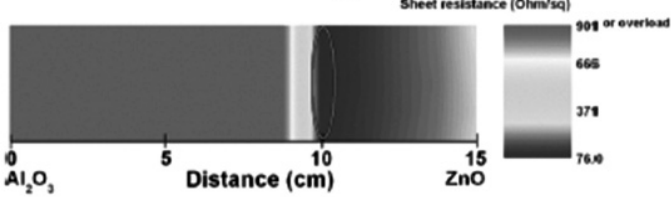

(c)

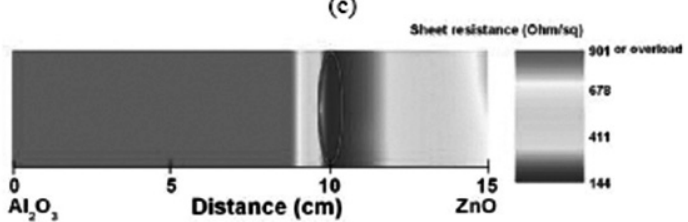

(d)

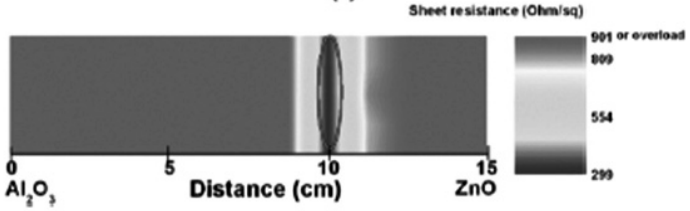

(e)

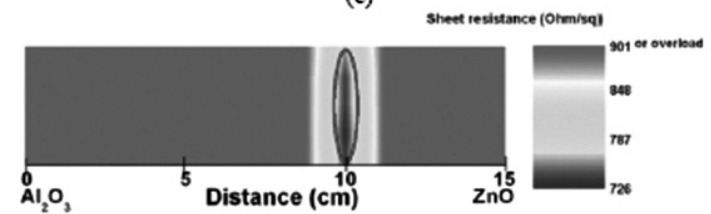

(f)

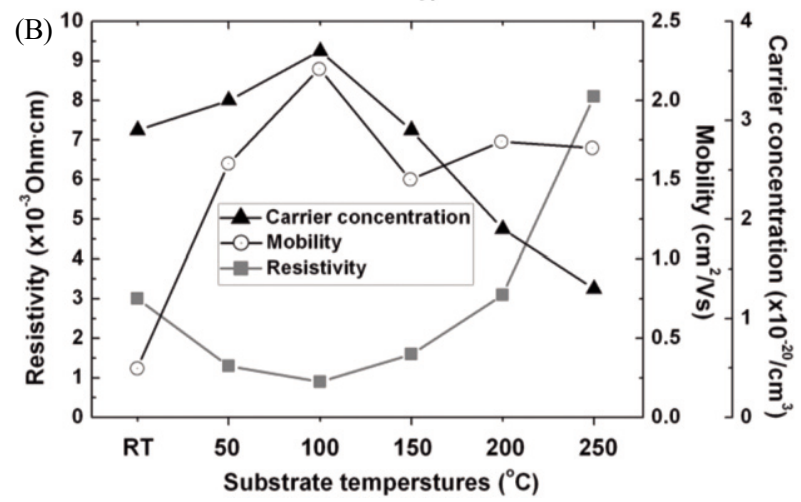

Fig. 3. (A) Sheet resistance map (B) resistivity (position of $10 \mathrm{~cm}$ ) of AZO-CCS thin films deposited at various substrate temperatures ; (a) R.T., (b) $50{ }^{\circ} \mathrm{C}$, (c) $100{ }^{\circ} \mathrm{C}$, (d) $150{ }^{\circ} \mathrm{C}$, (e) $200^{\circ} \mathrm{C}$, (f) $250{ }^{\circ} \mathrm{C}$

$\left.\times 10^{-4} \Omega \cdot \mathrm{cm}\right)$, carrier concentration $\left(3.7 \times 10^{20} \mathrm{~cm}^{-3}\right)$ and Hall mobility $\left(2.2 \mathrm{~cm}^{2} / \mathrm{V} \cdot \mathrm{s}\right)$ were obtained. On the other hand, it was observed that the resistivity increased as the substrate temperature increased above $100{ }^{\circ} \mathrm{C}$. The increase in the concentration is caused by the increase in the number of doped $\mathrm{Al}^{3+}$ ions into the $\mathrm{Zn}^{2+}$ sites when increasing substrate temperature up to $100{ }^{\circ} \mathrm{C}$. This behavior can be reasonably associated with the relative value of $\mathrm{Zn}$ and $\mathrm{Al}$ vapor pressures. The vapor pressure of $\mathrm{Al}$ remains below the chamber pressure even at the highest deposition temperature. However, the $\mathrm{Zn}$ vapor pressure is lower than the chamber pressure only for deposition temperatures below $100{ }^{\circ} \mathrm{C}$. Then, at a low substrate temperature film composition should be basically controlled by the atom flux impinging on the substrate from the plasma, thus allowing thin films to grow with the nominal Al content. At high substrate temperatures the growth rate is significantly reduced by $\mathrm{Zn}$ reevaporation[15].

Fig. 4 shows the XRD patterns(position of $10 \mathrm{~cm}$ for each AZO-CCS thin film) of AZO thin films prepared at substrate temperatures between $0{ }^{\circ} \mathrm{C}$ and $250{ }^{\circ} \mathrm{C}$. All AZO thin films deposited at substrate temperatures between 0 and $250{ }^{\circ} \mathrm{C}$ exhibit a highly preferred oriented (002) and a small (004) peak, which indicates that the films are highly oriented with their crystallographic c-axis perpendicular to the substrate. This can be inferred that the $\mathrm{Al}$ atoms dope the $\mathrm{Zn}$ site in the hexagonal lattice or probably segregate to the non-crystalline region in grain boundaries and form the $\mathrm{Al}-\mathrm{O}$ bond. It is believed that much of $\mathrm{Al}$ is able to be ionized into $\mathrm{Al}^{3+}$ and dope the $\mathrm{Zn}^{2+}$ site, so that it can contribute a free electron from each $\mathrm{Al}$ atom[16]. The best crystallinity was observed for the AZO thin film deposited at $100{ }^{\circ} \mathrm{C}$. Above $100{ }^{\circ} \mathrm{C}$, the intensity of the (002) peak decreased rapidly with increasing substrate temperatures because of the excess and difference regarding the $\mathrm{Zn}$ addition into AZO thin films[6].

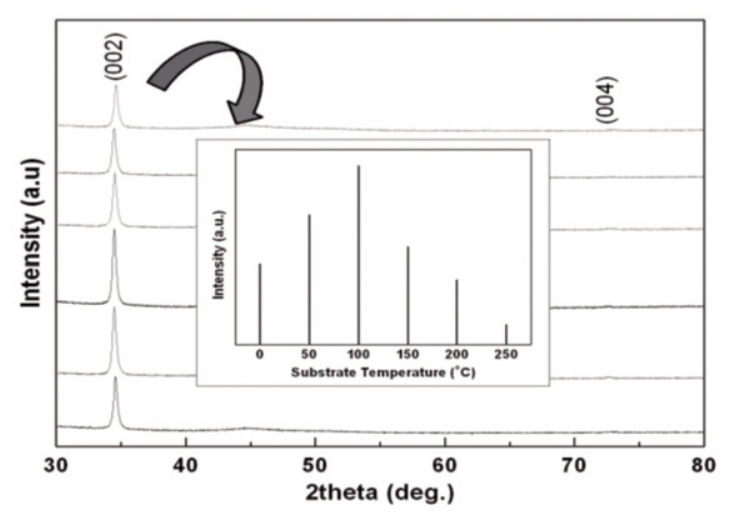

Fig. 4. XRD patterns of AZO-CCS thin films deposited at different substrate temperatures from $0{ }^{\circ} \mathrm{C}$ (bottom) to 250 ${ }^{\circ} \mathrm{C}$ (top), by turns. 

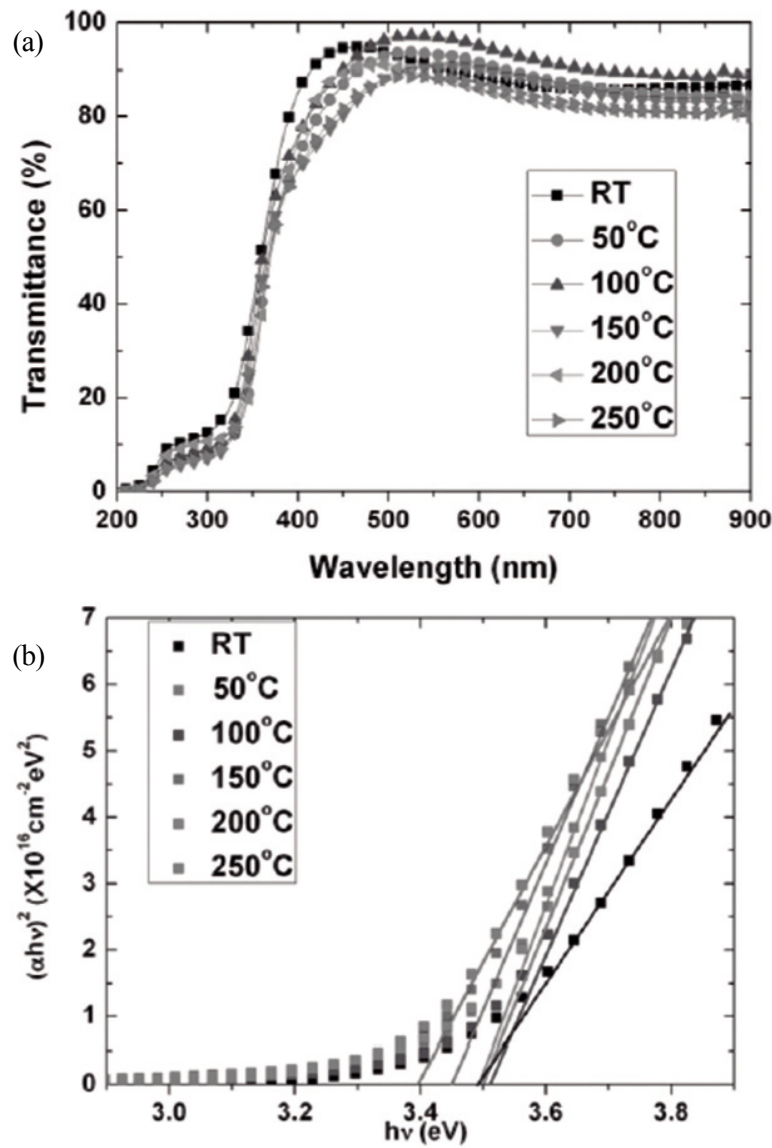

Fig. 5. (a) The optical transmittance (b) the $\alpha^{2}$ versus $\mathrm{h} \nu$ plot of AZO-CCS thin films deposited at different substrate temperatures between $0{ }^{\circ} \mathrm{C}$ and $250^{\circ} \mathrm{C}$.

Fig. 5(a) shows the optical transmittance of AZO thin films (position of $10 \mathrm{~cm}$ for each AZO-CCS thin film) deposited at substrate temperatures between 0 and $250{ }^{\circ} \mathrm{C}$. The average transmittance of all AZO thin films was over $84 \%$ in the $400 \mathrm{~nm}$ to $700 \mathrm{~nm}$ wavelength region. Also, the average transmittance of AZO thin film deposited at $100{ }^{\circ} \mathrm{C}$ which had the lowest resistivity was $92 \%$ in the $400 \mathrm{~nm}$ to $700 \mathrm{~nm}$ wavelength region.

Fig. 5(b) shows the $(\alpha \mathrm{h} \nu)^{2}$ versus $\mathrm{h} \nu$ plot of AZO thin films(position of $10 \mathrm{~cm}$ for each AZO-CCS thin film) deposited at substrate temperatures between 0 and $250{ }^{\circ} \mathrm{C}$. The optical absorption coefficient $\alpha$ can be obtained through $\mathrm{I}=\mathrm{I}_{0} \mathrm{e}^{-\alpha \mathrm{t}}$, where $\mathrm{I}$ is the intensity of transmitted light, $\mathrm{I}_{0}$ is the intensity of incident light, and $t$ is the thickness of the thin films. In the direct transition semiconductor, the absorption coefficient $(\alpha)$ follows the following relationship with the

$$
\text { optical band gap ; } \alpha h v=B\left(h v-E_{g}\right)^{1 / 2}
$$

where $E_{g}$ is the optical band gap energy, $\nu$ is the frequency of the incident photon, $h$ is Planck's constant, and $B$ is a constant which is related to the electron-hole mobility. The optical band gap can be determined through extrapolation of the linear region from the $(\alpha \mathrm{h} \nu)^{2}$ versus $\mathrm{h} \nu$ near the onset of the absorption edge to the energy axis. The band gap of the AZO thin film deposited at $100{ }^{\circ} \mathrm{C}$ was found to be $3.5 \mathrm{eV}$. Especially, the absorption onset for the increase of substrate temperatures up to $100{ }^{\circ} \mathrm{C}$ is slightly blue shifted which is associated with the increase in the carrier concentration blocking the lowest states in the conduction band, well known as the Burstein-Moss effect[17, 18].

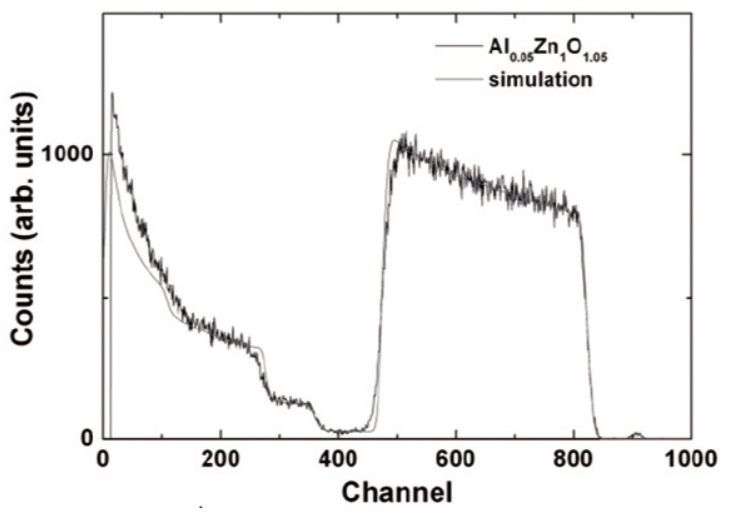

Fig. 6. $2 \mathrm{MeV}{ }^{4} \mathrm{He}^{++}$Rutherford backscattering spectrum of 740 $\mathrm{nm}$ thick AZO thin film(position of $9 \mathrm{~cm}$ ).

Fig. 6 shows that the compositional analysis was performed by Rutherford backscattering spectroscopy (RBS) for the $740 \mathrm{~nm}$ thick AZO film(position of $10 \mathrm{~cm}$ ) which had the best electrical and optical properties. RBS was carried out using $2 \mathrm{MeV}{ }^{4} \mathrm{He}^{++}$particles with a scattering angle of $170^{\circ}$. The composition of AZO film, 3.13 wt.\% $\mathrm{Al}$ doped $\mathrm{ZnO}$, was obtained from the RUMP code simulation.

In this field, there are a lot of reports about the optimized $\mathrm{Al}$ doping concentration and growth temperature. Thus, we investigated the full range of AZO compositions by continuous composition spread depending on substrate temperatures. Finally, the optimized substrate temperature of AZO film was $100^{\circ} \mathrm{C}$ at $3.13 \mathrm{wt} \% \mathrm{Al}$ doped $\mathrm{ZnO}$.

\section{CONCLUSIONS}

AZO thin films with varying substrate temperatures by the CCS method were investigated. The lowest resistivity 
and average transmittance at the 400 to $900 \mathrm{~nm}$ wavelength region of AZO thin film deposited at $100{ }^{\circ} \mathrm{C}$ was $9 \times 10^{-4}$ $\boldsymbol{\Omega} \cdot \mathrm{cm}$ and $92 \%$, respectively. This AZO thin film exhibits (002) and (004) peaks, which indicates that the films are highly oriented with their crystallographic c-axis perpendicular to the substrate. The best crystallinity was observed for the AZO thin film deposited at $100{ }^{\circ} \mathrm{C}$. The optimized composition (the lowest resistivity and highest transmittance) of the AZO thin film was $3.13 \mathrm{wt} \% \mathrm{Al}_{2} \mathrm{O}_{3}$ doped $\mathrm{ZnO}$.

\section{ACKNOWLEDGMENT}

This study was supported by "the Core Technology of Materials Research and Development Program(No. 10041 232) funded by the Ministry of Knowledge Economy, Republic of Korea.

\section{REFERENCES}

[1] S. Major, S. Kumar, M. Bhatnagar, and K. L. Chopra, "Effect of hydrogen plasma treatment on transparent conducting oxides", Appl Phys Lett., vol. 49, pp. 394396, 1986.

[2] G. H Kim, B. D. Ahn, H. S. Shin, W. H. Jeong, H. J. Kim, and H. J. Kim, "Effect of indium composition ratio on solution-processed nanocrystalline $\mathrm{InGaZnO}$ thin film transistors", Appl Phys Lett., vol. 94, pp. 233501.1-233501.3, 2009.

[3] H. L. Hartnagel, A. L. Dawar, A. K. Jain, and C. Jagadish, Semiconducting Transparent Thin Film, Bristol, U.K, 1995.

[4] S. Lee, H. Kim, D. -J. Yun, S. -W. Rhee, and K. Yong, "Resistive switching characteristics of $\mathrm{ZnO}$ thin film grown on stainless steel for flexible nonvolatile memory devices", Appl Phys Lett., vol. 95, pp. 262113.1-262113.3, 2009.

[5] T. Minami, H. Nanto, S. Shooji, and S. Takata, "The stability of aluminium-doped $\mathrm{ZnO}$ transparent electrodes fabricated by sputtering", Thin Solid Film, vol. 135, pp. 183-187, 1986.

[6] Y. H. Kim, K. S. Lee, T. S. Lee, B. Cheong, T. -Y. Seong, and W. M. Kim, "Effects of substrate temperature and $\mathrm{Zn}$ addition on the properties of $\mathrm{Al}$ doped ZnO films prepared by magnetron sputtering", Appl Surf Sci., vol. 255, pp. 7251-7256, 2009.
[7] A. Suzuki, M. Nakamura, R. Michihata, T. Aoki, T. Matsushita, and M. Okuda, "Ultrathin Al-doped transparent conducting zinc oxide films fabricated by pulsed laser deposition", Thin Solid Film, vol. 517, pp. 1478-1481, 2008.

[8] B. -Z. Dong, H. Hu, G. -J. Fang, X. -Z. Zhao, D. -Y. Zheng, and Y. -P. Sun, "Comprehensive investigation of structural, electrical, and optical properties for $\mathrm{ZnO}$ :Al films deposited at different substrate temperature and oxygen ambient", J. Appl. Phys., vol. 103, pp. 073711-073718, 2008.

[9] R. B. van Dover, L. F. Schneemeyer, and R. M. Fleming, "Discovery of a useful thin-film dielectric using a composition-spread approach", Nature, vol. 392, pp. 162-164, 1998.

[10] S. Yaginuma, K. Itaka, Y. Matsumoto, T. Ohnishi, M. Lippmaa, T. Nagata, T. Chikyowe, and H. Koinuma, "Composition-spread thin films of pentacene and 6,13-pentacenequinone fabricated by using continuous-wave laser molecular beam epitaxy", Appl Surf Sci., vol. 254, pp. 2336-2341, 2008.

[11] I. Ohkubo, H. M. Christen, P. Khalifah, S. Sathyamurthy, H. Y. Zhai, C. M. Rouleau, D. G. Mandrus, and D. H. Lowndes, "Continuous composition-spread thin films of transition metal oxides by pulsed-laser deposition", Appl Surf Sci., vol. 223, pp. 35-38, 2004.

[12] R. B. van Dover, L. F. Schneemeyer, R. M. Fleming, and H. A. Huggins, "A high-throughput search for electronic materials-thin-film dielectrics", Biotechnology and Bioengineering, vol. 61, pp. 217225, 1999.

[13] X.-D. Xiang and I. Takeuchi, ed., Combinatorial Materials Synthesis, Marcel Dekker, Inc., New York, pp. 34-54, 2003.

[14] P. A. Sánchez, T. Sintes, J. H. E. Cartwright, and O. Piro, "Influence of microstructure on the transitions between mesoscopic thin-film morphologies in ballistic-diffusive models", Phys. Rev. E, vol. 81, pp. 011140-011150, 2010.

[15] J.A. Sans, J.F. Sánchez-Royo, V. Barber, M.A. Hernández-Fenollosa, B. Marí, and A. Segura, "Correlation between optical and transport properties of Ga-doped $\mathrm{ZnO}$ thin films prepared by pulsed laser deposition", Superlattices and Microstructures, vol. 39, pp. 282-290, 2006.

[16] H. T. Cao, Z. L. Pei, J. Gong, C. Sun, R. F. Juang, and L. S. Wen, "Transparent conductive Al and Mn doped 
$\mathrm{ZnO}$ thin films prepared by DC reactive magnetron sputtering”, Surf. Coat. Technol., vol. 184, pp. 84-92, 2004.

[17] E. Burstein, “Anomalous optical absorption limit in
InSb", Phys. Rev., vol. 93, pp. 632-633, 1954.

[18] T. S. Moss, "The Interpretation of the Properties of Indium Antimonide", Proc. Phys. Soc. B, vol. 67, pp. 775-782, 1954.

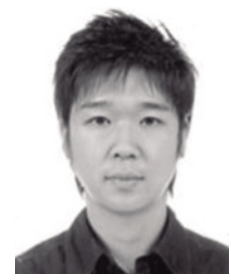

Keun Jung received a BS degree from the Suwon University, Republic of Korea, in 2009. In 2011, he received his MS degree from Yonsei University and KIST. He is currently working on the development of TCO in LG Hausys.

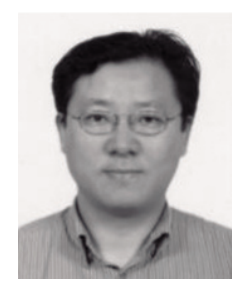

Won-Kook Choi received his Ph.D. degree(1993) in Surface Physics from Yonsei University following a M.S. degree(1986) in Applied Physics and B.S. degree(1984) in Physics from Yonsei University. He joined the University of Oregon in 1993 to 1994 and KIST in 1994 to 1996 as a postdoctoral fellow. He began as a senior researcher in KIST(1996) and conducted research in surface modification by low energy ion beams and oxide semiconductor-based micro-chemical sensors. Also he developed the $\mathrm{ZnO}$ based light emitting diode and the cluster ion beam for ultra surface smoothing, ultra shallow junction formation. He is currently exploiting synthesis of oxide semiconductornanocarbon(graphene, CNT, C60) core shell quantum dots for the application of QD LED, UV sensor, and next generation memory devices.

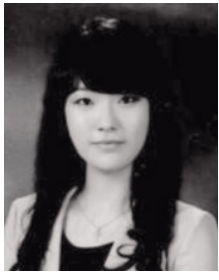

Jin-Ju Lee received a BS degree from the Chungbuk National University, Republic of Korea, in 2011. She is currently a Masters course student at Yonsei University and KIST. Her research topic is oxide semiconductor.

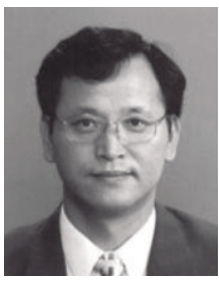

Seok-Jin Yoon received his Ph.D. degree(1992) in Electrical Engineering from Yonsei University following a M.S. degree(1985) and B.S. degree (1983) in Electrical Engineering from Yonsei University. He joined Korea Institute of Science and Technology (KIST) in 1988, where he conducted research in the science and technology of piezoelectric materials and actuators, ferroelectric, microwave dielectrics and devices. He was a director of the Thin Film Materials Research Center and Future Convergence Research Division. $\mathrm{He}$ is currently a director of Research Planning \& Coordination Division. 
Ji-Won Choi received his Ph.D. degree(2002) in Ceramic Engineering from Yonsei University following a M.S. degree(1994) and B.S. degree (1989) in Ceramic Engineering from Yonsei University. He joined Cornell University as a post doctoral fellow in 2004 to 2005 . He joined Korea Institute of Science and Technology(KIST) in 1994, where he conducted research in the science and technology of microwave dielectric, piezoelectric, transparent conducting oxide, thin film rechargeable batteries, and nano-sheet materials and devices. He is currently exploiting high-throughput techniques for the discovery of novel inorganic materials including dielectrics, optical materials as well as electrodes for Liion batteries. 